\title{
Substrate-induced volatile organic compound emissions from compost-amended soils
}

\author{
Martin S. A. Seewald • Wolfgang Singer • \\ Brigitte A. Knapp • Ingrid H. Franke-Whittle • \\ Armin Hansel $\cdot$ Heribert Insam
}

Received: 7 September 2009/Revised: 18 January 2010/Accepted: 21 January 2010 / Published online: 20 February 2010

(C) The Author(s) 2010. This article is published with open access at Springerlink.com

\begin{abstract}
The agronomic effects of composts, mineral fertiliser and combinations thereof on chemical, biological and physiological soil properties have been studied in an 18-year field experiment. The present study aimed at tracing treatment effects by evaluating the volatile organic compound (VOC) emission of the differently treated soils: non-amended control, nitrogen fertilisation and composts (produced from organic waste and sewage sludge, respectively) in combination with nitrogen fertiliser. Microbial community structure was determined by denaturing gradient gel electrophoresis (DGGE). Aerobic and anaerobic soil VOC emission was determined after glucose amendment using proton transfer reaction-mass spectrometry (PTR-MS). After inducing VOC production by substrate (glucose) addition and at the same time reducing oxygen availability to impair degradation of the produced VOCs, we were able to differentiate among the treatments. Organic waste compost did not alter the VOC emissions compared to the untreated control, whilst sewage sludge composts and mineral fertilisation showed distinct effects. This differentiation was supported by DGGE analysis of fungal $18 \mathrm{~S}$ rDNA fragments and confirms earlier findings on bacterial communities. Three major conclusions can be drawn: (1) VOC patterns are able to discriminate among soil treatments. (2) Sewage sludge compost and mineral fertilisation have not only the strongest impact on microbial community
\end{abstract}

\footnotetext{
M. S. A. Seewald $(\bowtie) \cdot$ B. A. Knapp • I. H. Franke-Whittle •

H. Insam

Universität Innsbruck,

Innsbruck, Austria

e-mail: csae3123@uibk.ac.at

W. Singer $\cdot$ A. Hansel

Ionimed Analytik GmbH,

Innsbruck, Austria
}

composition but also on VOC emission patterns, but specific tracer VOCs could not be identified. (3) Future efforts should aim at a PTR-MS-linked identification of the detected masses.

Keywords VOC.PTR-MS · Compost .

Soil microbial community structure

\section{Introduction}

Permanent agricultural use of soil decreases nutrient and soil organic matter contents (Chan et al. 2002). To maintain plant nutrient contents, in most cases, mineral fertilisers are used, whilst the role of soil organic matter as an essential determinant of soil fertility and stability is often underestimated (Ros et al. 2006a). To build up soil organic matter in arable soils - a process much slower than its degradation-modern farming approaches include a sustainable management of soils to maintain the longterm productivity. Amongst the options is to reduce the use of mineral fertilisers and replace them by organic fertilisers and/or composts, often produced from agricultural or domestic residues (Garcia et al. 1994; Pascual et al. 1997). In particular, soils with a low soil organic matter (SOM) content (e.g. below 2\%) benefit from organic matter input (Lal 2005; Roldan et al. 2005; Ros et al. 2006a). Besides this, conversion of organic residues such as sewage sludge, green cut, organic wastes or animal manure into useable composts reduces the amount of waste deposed into landfill sites, thereby improving the cycling of matter. Besides these known benefits, soil compost and fertiliser amendments affect the soil microbial community composition and activity in different ways, as has been shown by Innerebner et al. (2006) and Ros et al. (2006a, 
b). Microbiological tools range from conventional cultivation approaches to molecular techniques, each of them with its own advantages, biases and limitations. Identification and characterisation of the microbial community from differently treated arable soils can help to detect sources for human and plant pathogens and is thus needed for the regulation of compost application.

Microorganisms are known to produce a great variety of different compounds. Many of those are volatile, which is making them easily accessible for detection prior to any visible signs of microbial growth. The detection of volatile organic compounds (VOCs) by various approaches has long been practised (e.g. Brown 1922 cited in Linton and Wright 1993), but recently, new detection methods have increased the potential of such studies. In addition to molecular tools targeting microbial community structure, VOCs may help to detect the presence of certain microorganisms as microbial VOCs emerge from various habitats like soil (Schade and Custer 2004; Asensio et al. 2007a), litter (Leff and Fierer 2008), food (Börjesson et al. 1990, 1992; Kershi et al. 1998; Schnürer et al. 1999; Gao and Martin 2002; Mayr et al. 2003), composts (Wheatley et al. 1997; Fischer et al. 1999; Smet et al. 1999), buildings (Wilkins et al. 2000; Fischer and Dott 2003; Matysik et al. 2008), plant surfaces (Tirranen and Gitelson 2006), domestic biowaste (Mayrhofer et al. 2006), arctic ice (Dickschat et al. 2005a), seawater (Dickschat et al. 2005b) and air conditioning systems of cars (Rose et al. 2000). Volatile organic compounds is a broad term defining a large group of compounds, including metabolites produced by all life forms. It has been suggested by several authors that some microorganisms may produce specific VOCs, making it possible to determine their identity by detecting certain VOCs (Isidorov and Jdanova 2002; Smolander et al. 2006; Bunge et al. 2008).

Proton transfer reaction mass spectrometry (PTR-MS) allows the online measurement of VOCs down to the parts per trillion by volume (pptv) level (Hansel et al. 1995, 1998; Lindinger et al. 1998). The main advantage of this method is the soft ionising reaction (a proton transfer from $\mathrm{H}_{3} \mathrm{O}^{+}$directly to the compounds) which uses low reaction energy and therefore reduces the number of gas molecules that get fragmented. The abundance of any trace gases measured has to be determined indirectly via the comeasurement of standards (trace gases of known amount) as the PTR-MS detects any trace gas as $m / z$ (mass-to-charge ratio) via an electron multiplier. Also, the identification of any compound is restricted to the analysis of the mass (most often assumed to be $(m / z-1)$ ) and the mass spectra (if available) of any compound. Another advantage of the PTR-MS method is the ability to measure online, allowing a more detailed view on the temporal dynamics of microbial VOC production (Bunge et al. 2008).
The aims of this study were to evaluate if the different amendments (mineral $\mathrm{N}$ fertiliser, municipal organic waste compost and sewage sludge compost) could be distinguished by VOC emission patterns as well as elucidating types and amounts of VOCs produced by the soils. Besides the fact that PTR-MS has been used for the determination of soil-derived VOCs only by a few scientists so far (Ezra et al. 2004; Schade and Custer 2004; Asensio et al. 2007a, b), another innovative concept of this study was the use of anaerobic and substrateinduced approaches for VOC measurements. As suggested by several authors (Larsen and Frisvad 1995a, b; Fischer et al. 1999; Fiedler et al. 2001), VOCs could be used to identify certain fungi back to species level. Therefore, our second objective was to link specific VOCs to changes in the composition of fungal communities determined by denaturing gradient gel electrophoresis (DGGE).

\section{Materials and methods}

Soil samples were taken at the research site "Ritzlhof" near Linz, Upper Austria. The site is part of a crop rotation fertilisation experiment (grain maize, summer wheat and winter barley) that was started in 1991 by the Austrian Agency for Health and Food Safety. The soil is a loamy silt with a pH of $6.8( \pm 0.4)$, an organic matter content of $1.9 \%$ (Ros et al. 2006a; Innerebner et al. 2006) and a water holding capacity of $0.5 \mathrm{~g} \mathrm{H}_{2} \mathrm{O}$ per gram dry soil. Soil characteristics and heavy metal contents are described in Ros et al. (2006a). Compost amendment takes place once a year in spring or autumn, followed by tilling (20 to $40 \mathrm{~cm}$ depth) shortly before crop planting. Each fertilisation treatment was applied on four randomly distributed replicate plots $(6 \times 5 \mathrm{~m}$ each). For this investigation, the following treatments were selected: (1) unfertilized control (control), (2) mineral fertiliser (ammonium nitrate, $\mathrm{NH}_{4} \mathrm{NO}_{3}$, applied at $80 \mathrm{~kg} \mathrm{~N}$ per hectare; $80 \mathrm{~N}$ ), (3) combined amendment of mineral fertiliser ( $80 \mathrm{~kg} \mathrm{~N}$ per hectare) plus one of two different composts corresponding to a total of $175 \mathrm{~kg} \mathrm{~N}$ per hectare: urban organic waste compost $(\mathrm{OWC}+80 \mathrm{~N})$ and sewage sludge compost $(\mathrm{SSC}+80 \mathrm{~N})$.

Soil samples were collected in October 2008 prior to seeding. To obtain representative samples, five randomly taken soil cores (1- to $15-\mathrm{cm}$ depth) per plot were pooled to give one sample. The samples were stored at $4^{\circ} \mathrm{C}$ overnight. Small aliquots of samples for DNA analysis were kept frozen at $-20^{\circ} \mathrm{C}$.

The samples for VOC analysis were sieved (grid size $2 \mathrm{~mm}$ ), divided into portions of $100 \mathrm{~g}$ (equal to $\sim 80 \mathrm{~g}$ dry weight) and further stored at $4{ }^{\circ} \mathrm{C}$. Prior to infrared gas analysis (IRGA) or PTR-MS measurement, the samples 
were equilibrated to room temperature $2 \mathrm{~h}$ before the measurement started.

Water holding capacity (WHC), dry weight and water content were estimated gravimetrically. For estimating the soil moisture at $100 \%$ WHC, glass tubes were filled with soil, saturated with distilled water and allowed to drain for $2 \mathrm{~h}$ on silica sand (Leff and Fierer 2008).

DNA extraction was performed using the PowerSoil DNA Isolation Kit (MoBio Laboratories Inc., USA) according to the manufacturer's protocol, with three alterations: (1) Instead of using the FastPrep instrument for high-speed shaking, the tubes were shaken horizontally on a MM2000 shaker (Retsch, Haan, Germany) for $15 \mathrm{~min}$ at $60 \mathrm{rpm}$. (2) After addition of solution C5 (step 16), the tube was centrifuged for 1 min instead of $30 \mathrm{~s}$. (3) Instead of eluting the DNA bound to the membrane with $100 \mu 1$ solution C6 (step 20), $50 \mu \mathrm{l}$ of $60^{\circ} \mathrm{C}$ warm DNase-free water was used twice and collected in two different Eppendorf tubes. DNA yield and quality were assessed by electrophoresis on a $1.0 \%(w / v)$ agarose gel followed by DNA concentration measurements using PicoGreen dsDNA quantitation reagent (Invitrogen, USA).

Extracted DNA was amplified in a PCR thermocycler (FlexCycler $^{\mathrm{TM}}$, Analytik Jena AG, Germany). Each PCR mixture had a reaction volume of $25 \mu$ l containing $1.25 \mathrm{U}$ BioTherm $^{\mathrm{TM}}$ DNA Polymerase (genXpress, Austria), $200 \mu \mathrm{M}$ dNTP mix, $200 \mathrm{nM}$ of each primer, $20 \mu \mathrm{g}$ BSA (301 nM), $40 \mu \mathrm{g}$ DMSO, $1 \mathrm{mM} \mathrm{MgCl} 2,1 \times$ PCR buffer (genXpress) and 1-10 ng of template. For amplification of the fungal 18S rDNA, the primers FR1-GC (CCC CCG CCG CGC GCG GCG GGC GGG GCG GGG GCA CGG GCC GAI CCA TTC AAT CGG TAI T) and FF390 (CGA TAA CGA ACG AGA CCT; Vainio and Hantula 2000) were used. The PCR programme was conducted with an initial denaturation step at $95^{\circ} \mathrm{C}$ for $8 \mathrm{~min}$, followed by 35 thermal cycles of $30 \mathrm{~s}$ at $94^{\circ} \mathrm{C}$ and $45 \mathrm{~s}$ at $48^{\circ} \mathrm{C}$, and $3 \mathrm{~min}$ at $72^{\circ} \mathrm{C}$ and a final extension step at $72^{\circ} \mathrm{C}$ for $10 \mathrm{~min}$ were chosen. For amplification of the fungal rDNA internal spacer (ITS) region DNA fragments, a semi-nested approach as described by Bastias et al. (2006) was used. PCR was conducted using a FlexCycler ${ }^{\mathrm{TM}}$ PCR thermocycler (Analytik Jena AG), and products were checked by electrophoresis in $1.5 \%(w / v)$ agarose gels following ethidium bromide staining $\left(10 \mathrm{mg} \mathrm{ml}^{-1}\right.$ ), as well as quantified using PicoGreen dsDNA quantitation reagent (Invitrogen).

DNA fragments were subjected to DGGE (Muyzer et al. 1993). The acryl amide (7\%) gel with a 30-60\% denaturing gradient $(100 \%$ denaturant is $7 \mathrm{M}$ urea plus $40 \%$ formamide in $1 \times \mathrm{TAE}$ ) was run for $16 \mathrm{~h}$ at $60^{\circ} \mathrm{C}$ and $100 \mathrm{~V}$ on an IngenyPhorU2 system (Ingeny International $\mathrm{BV}$, the Netherlands).

Gels were stained with silver nitrate (Sanguinetti et al. 1994) using an automated gel stainer (Hoefer, Amersham
Pharmacia Biotech, USA). The stained gels were photographed, dried and scanned.

Images of the gels were analysed by the software package GelComparII, version 4.0 (Applied Maths, Ghent, Belgium). The bands were designated manually to be able to exclude artefacts deriving from gel staining or imaging. Prior to cluster analysis, the band matching task was deployed to align bands from different lanes to one certain position. Band matching was performed using an optimisation value of $1 \%$ and a position tolerance of $1 \%$. Similarity calculation was based on the Dice coefficient (Legendre and Legendre 1998) and resulted in a distance matrix, visualised in dendrograms calculated using the Ward algorithm (Legendre and Legendre 1998).

Basal respiration was determined by $\mathrm{CO}_{2}$ evolution from sieved (Ø $2 \mathrm{~mm}$ ), moist soil samples $(50 \%$ of maximal WHC) at $22^{\circ} \mathrm{C}$ after a 6 -h pre-incubation period with a continuous flow IRGA system (Heinemeyer et al. 1989). Plastic tubes were filled with $100 \mathrm{~g}$ moist samples, and $\mathrm{CO}_{2}$ production was measured hourly for $15 \mathrm{~h}$ under permanent humid air flow. All data are given on a soil dry mass basis.

Microbial biomass carbon $\left(C_{\text {mic }}\right)$ was determined by substrate-induced respiration. Forty grams (DM) of moist soil was mixed with $1 \%(w / w)$ glucose (Anderson and Domsch 1978), and the substrate-induced $\mathrm{CO}_{2}$ production rate was determined $6 \mathrm{~h}$ after glucose amendment (Heinemeyer et al. 1989).

To test if the different soil treatments had an impact on $C_{\text {mic }}$ or basal respiration rates, analysis of variance (ANOVA, $p<0.05$ ) was performed with SPSS version 15.0 (SPSS Inc., USA). Homogeneity of variances was tested with Levene test, and post hoc analysis was performed with Tukey HSD test.

For the PTR-MS and PTR-time-of-flight (TOF)-MS measurements (Lindinger et al. 1998), approximately $100 \mathrm{~g}$ of samples was filled in Teflon cylinders. Preliminary tests showed that only after addition of could glucose measurable VOC concentrations be obtained. In addition, the number of detected VOCs was considerably higher for anaerobic (using $\mathrm{N}_{2}$ for purging) than aerobic conditions. Thus, this setup was chosen for the present study. The cylinders were kept in the dark and in a water bath to maintain a constant temperature of $25^{\circ} \mathrm{C}$. Four samples were analysed per batch. All cylinders were purged with $70 \mathrm{ml} \mathrm{min}{ }^{-1} \mathrm{~N}_{2}$ for anaerobic measurements. During the measurement, the cylinder under investigation was connected to the PTR-MS for approximately $10 \mathrm{~min}$. The influx gas was humidified using a water-filled bottle (bubbler) before passing through a charcoal filter and a platinum catalyst $\left(400^{\circ} \mathrm{C}\right)$ to remove all VOCs from the carrier gas. Each sample was screened hourly for several 
masses between $18 \mu$ and $200 \mu$ for a period of at least $40 \mathrm{~h}$ after glucose amendment.

The PTR-MS drift tube was operated at $2.2 \mathrm{mbar}$ and at $60^{\circ} \mathrm{C}$. The drift voltage was $600 \mathrm{~V}$ giving an $\mathrm{E} / \mathrm{N}$ (electric field strength across the reaction chamber to buffer gas number density within the chamber) of approximately $120 \mathrm{Td}\left(1 \mathrm{Td}=10 \mathrm{e}^{-17} \mathrm{~V} \mathrm{~cm}^{2}\right)$.

Volatile organic compound identification was performed using the molecular weight data from PTR-MS and PTR-TOF-MS measurements. Possible sum formulas were calculated using Molecular Fragment Calculator 1.0 (C) James E. Deline, Windows Version by Dwight L Smith). Molecular conformations were aligned using NIST Standard Reference Database Number 69.

The PTR-MS-derived datasets were normalised so the unit of abundance was normalised counts per second (ncps). All masses deriving from water clusters $(19,21$, 37, 39 and 55) were eliminated. ANOVA and post hoc tests were performed using SPSS version 15.0 (SPSS Inc.). Calculations were performed using the time chart dataset for all detected masses as well as curve parameters such as the absolute peak height (data not shown). To summarise differences in VOC emissions between the different treatments, principal component analysis (PCA) was calculated from total VOC abundance data of all relevant masses (except water clusters). The PCA data were visualised using a multidimensional scaling approach (Fig. 6) where the distances between the objects (replicates of the different treatments) were calculated as Euclidean distances.

\section{Results}

Analysis of microbial community structure by PCR-DGGE

The DGGE fingerprints of the ITS region from the different samples and replicates appeared not to be very different (Fig. 1). All samples contained a high number of bands in the upper and middle sections of the gel and a smaller number of bands in the high-GC section of the gel. Nevertheless, analysis of banding patterns resulted in the formation of three main clusters: $80 \mathrm{~N}$ and $\mathrm{SSC}+80 \mathrm{~N}$ replicates grouped separately from the cluster formed by OWC $+80 \mathrm{~N}$ and control samples that formed two subclusters with a similarity of $76 \%$. The diversity between replicates of any treatment was relatively high, ranging from $78 \%$ to $95 \%$.

The DGGE fingerprints of the 18S rDNA (data not shown) showed similar groupings. However, differences within the groups were higher and showed similarities from $83 \%$ to $97 \%$. Most bands occurred in different intensities, but were present in almost every lane. Control and $\mathrm{OWC}+80 \mathrm{~N}$ samples showed a similarity of
$65 \%$, whilst the $\mathrm{SSC}+80 \mathrm{~N}$ and $80 \mathrm{~N}$ samples grouped more distantly.

Basal respiration rates and microbial biomass

Sewage sludge compost-amended samples showed the highest basal respiration and microbial biomass, $0.7 \mu \mathrm{g} \mathrm{CO}_{2}$ per gram soil per hour and $75 \mu \mathrm{g} C_{\text {mic }}$ per gram soil, respectively. The samples collected in October 2008 showed significant differences between control and $\mathrm{OWC}+80 \mathrm{~N}$, control and $\mathrm{SSC}+80 \mathrm{~N}, 80 \mathrm{~N}$ and $\mathrm{OWC}+80 \mathrm{~N}$ as well as $80 \mathrm{~N}$ and SSC $+80 \mathrm{~N}$. In other words, the compost-amended soils differed significantly from the control and the mineral fertilised soil as they had higher microbial biomass contents and basal respiration (Fig. 2).

For all treatments, microbial biomass $(r=0.60, p<0.05)$ and basal respiration $(r=0.61, p<0.05)$ were positively correlated with total VOC production.

VOCs detected and compound identification

When samples were not amended with glucose, the VOC emissions of the soil samples were below the detection limit of the PTR-MS. The results discussed below thus refer only to measurements after glucose amendment. Under anaerobic conditions, a considerable number of masses (39) showed high abundance (>10 ncps; Fig. 3). The masses with the highest abundance $\left(>10^{3}\right.$ ncps $)$ under anaerobic conditions were $m / z 47,59,57,45,43$ and 41 . In contrast, under aerobic conditions, only four masses $(\mathrm{m} / \mathrm{z} 59,45,33$ and 47) exceeded 10 ncps.

All masses detected with PTR-MS under anaerobic conditions range from $\mathrm{m} / \mathrm{z} 30$ to $\mathrm{m} / \mathrm{z} 120$. The six masses exceeding $10^{3}$ ncps were chemically identified or at least limited to certain sum formulas. For mass 57, four different compounds matched the identified sum formula: propenal or methylketene $\left(\mathrm{C}_{3} \mathrm{H}_{4} \mathrm{O}\right)$ and butene or propene $\left(\mathrm{C}_{4} \mathrm{H}_{8}\right)$. Both masses 43 and 41 did not show any feasible match, but molecules of higher weight tend to break up in fragments of this size, e.g. acetic acid, propanol or propandiol. Mass 47 would be that of ethanol and formic acid, being both end products of the anaerobic energy chain. Mass 59 would be due to acetone, whereas mass 45 would be that of three potential compounds: acetaldehyde, propane and vinyl alcohol; however, acetaldehyde seems to be the most logic candidate as it is formed as intermediate product of ethanol degradation.

Volatile organic compound emission patterns and dynamics

Due to its limited compound identification capabilities, specific masses cannot be unambiguously assigned to a certain substance. However, some masses could at least be 


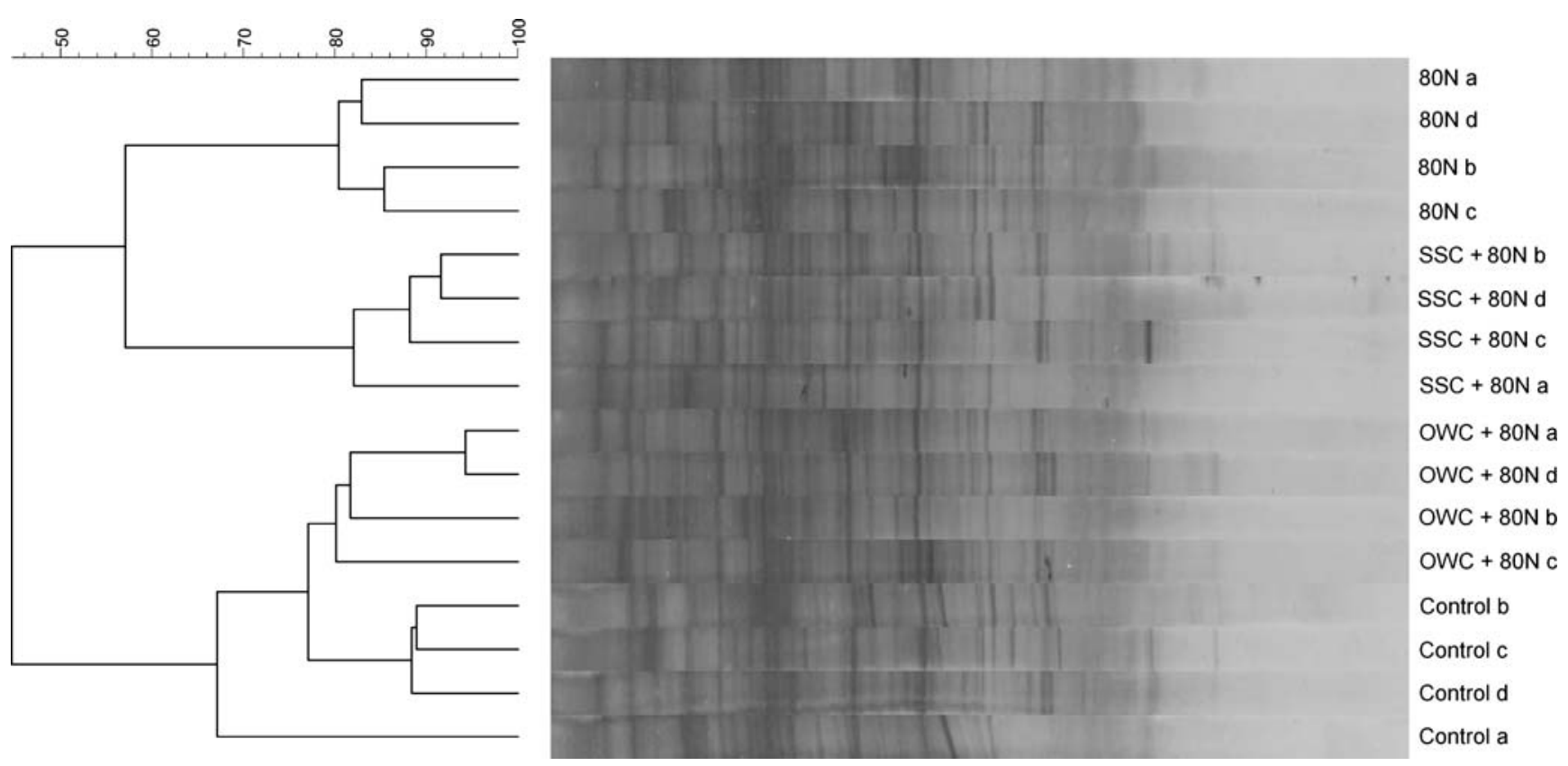

Fig. 1 Cluster analysis of DGGE fingerprints based on fungal ITS DNA fragments from four replicates $(n=4)$ and bars of four differently treated soils (non-amended control: control; mineral

tentatively identified. Volatile organic compound emission patterns (maximum peak height of all masses found) varied among the different treatments (Fig. 4). The patterns of the control and $\mathrm{OWC}+80 \mathrm{~N}$ samples were quite similar, whilst the $80 \mathrm{~N}$ and the $\mathrm{SSC}+80 \mathrm{~N}$ samples deviated considerably. The $\mathrm{SSC}+80 \mathrm{~N}$ samples showed the highest number of different masses. Compared to the $\mathrm{SSC}+80 \mathrm{~N}$ samples, masses 72, 77, 85 and 88 were absent in all control replicates, and mass 72 and 85 were missing in all $\mathrm{OWC}+$ $80 \mathrm{~N}$ replicates. But there were also masses missing in, one, two or three replicates of a treatment only, like masses 51, $66,93,101$ and 103, which were missing in some of the

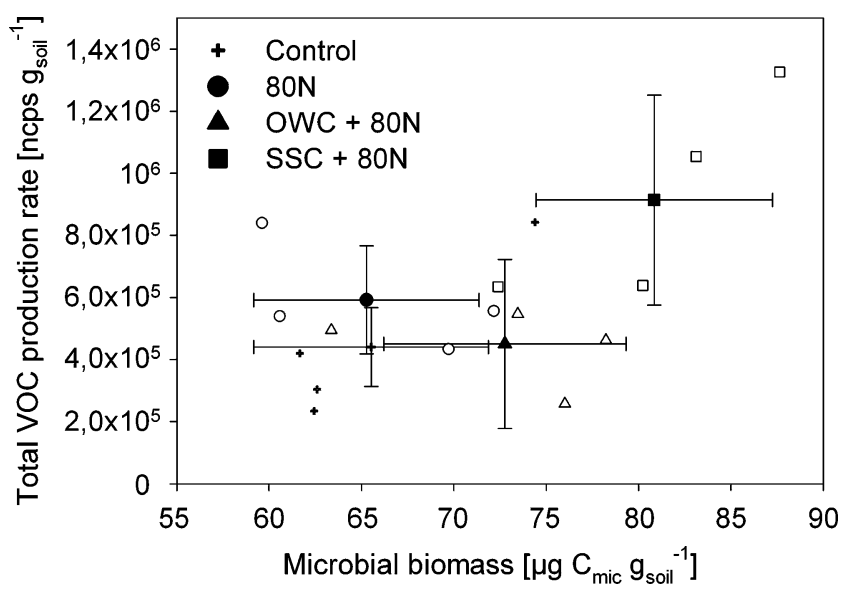

Fig. 2 Comparison of the total VOC production rate and the microbial biomass $\left(C_{\text {mic }}\right)$ of four differently treated soils. The values are means over all replicates $(n=4)$. Bars are standard deviations nitrogen-amended: $80 \mathrm{~N}$; urban organic waste compost plus mineral fertiliser: $\mathrm{OWC}+80 \mathrm{~N}$ and sewage sludge compost plus mineral fertiliser: $\mathrm{SSC}+80 \mathrm{~N})$

control replicates (Fig. 4). Similarly, masses 62, 77, 101 and 103 were missing in some $\mathrm{OWC}+80 \mathrm{~N}$ replicates, and masses 72, 77, 85 and 88 were below the limit of detection in some $80 \mathrm{~N}$ replicates.

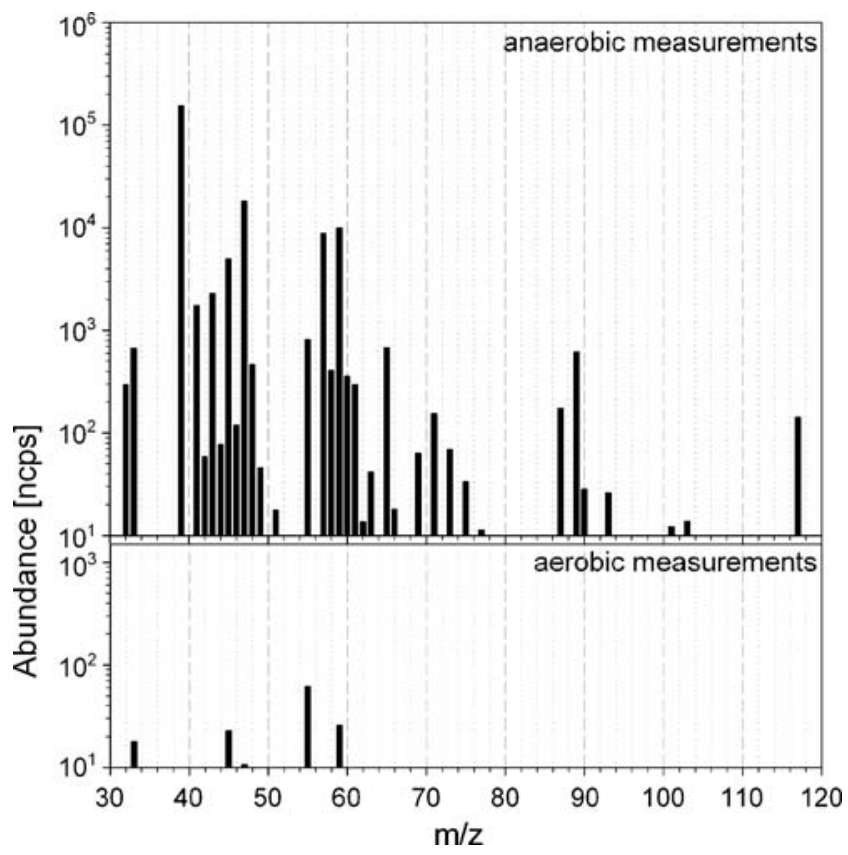

Fig. 3 Comparison of measurements under anaerobic and aerobic conditions. The abundance (ncps normalised counts per second) of different masses ( $\mathrm{m} / \mathrm{z}$ mass-to-charge ratio) are shown here. Measurements took place under anaerobic and aerobic conditions. The values shown here are the average of peak maximums of all four treatments and its parallels. All ncps values correspond to $100 \mathrm{~g}$ soil 


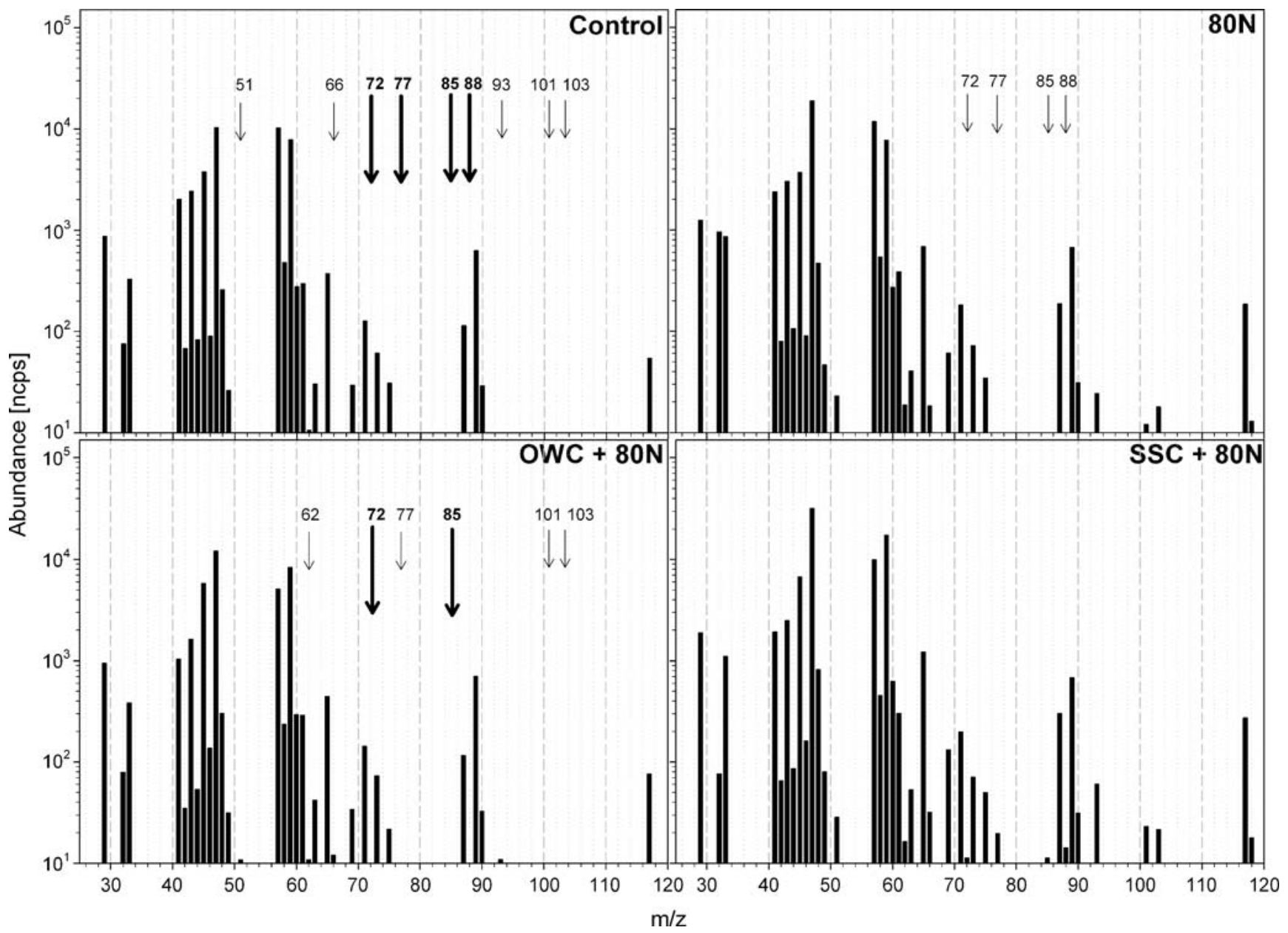

Fig. 4 Mass spectra of four different treatments control, $(80 \mathrm{~N})$ mineral $\mathrm{N}$ fertiliser, $(\mathrm{OWC}+80 \mathrm{~N})$ mineral $\mathrm{N}$ plus urban organic waste compost and $(\mathrm{SSC}+80 \mathrm{~N})$ mineral $\mathrm{N}$ plus sewage sludge compostamended samples, determined under anaerobic measurement conditions. The abundances are given as maximum ncps of averaged

Temporal VOC charts revealed differences between the different treatments as well as between different masses (Fig. 5). The abundance of certain masses varied strongly within the replicates of one treatment, but the shapes of the curves were similar. For example, the $\mathrm{SSC}+80 \mathrm{~N}$ replicates of m45 show very similar time progression with a VOC production starting at $15 \mathrm{~h}$, a maximum at $26 \mathrm{~h}$ and a final decrease until $40 \mathrm{~h}$ after glucose amendment (Fig. 5). The time chart for $\mathrm{m} 47$ looks different as the production starts at $14 \mathrm{~h}$ after glucose amendment, thus not even reaching a maximum within $40 \mathrm{~h}$. The treatments differed markedly in VOC abundance and in the shapes of the curves.

ANOVA over all time points, treatments and masses did not show any significant differences at all. However, ANOVA using maximal abundances of all masses showed significant differences among the treatments. Principal component analysis over all masses that showed significant differences between treatments resulted in the formation of parallels for each mass $(\mathrm{m} / \mathrm{z})$ that occurred with more than $10 \mathrm{ncps}$. All ncps values are corresponding to $100 \mathrm{~g}$ soil. Missing masses are indicated with bold arrows. Masses below the detection limit in some replicates are labelled with arrows

three groups (Fig. 6); $\mathrm{SSC}+80 \mathrm{~N}$ and $80 \mathrm{~N}$ samples were clearly separated from the control and the OWC treatments. The placement of $\mathrm{SSC}+80 \mathrm{~N}$ samples towards the positive end of the plot along dimension 1 indicates that these samples produced the masses contributing to dimension 1 in highest amounts. The placement of the other samples in the biplot allows similar interpretations concerning the production of VOCs for all samples.

\section{Discussion}

Analysis of microbial community structure by DGGE

DGGE fingerprints from ITS and 18SSU rDNA fragments appeared to be complex, reflecting the high diversity of soil fungi. Most bands occurred in all lanes, differing slightly in their intensity, indicating the soil fungal community to be 


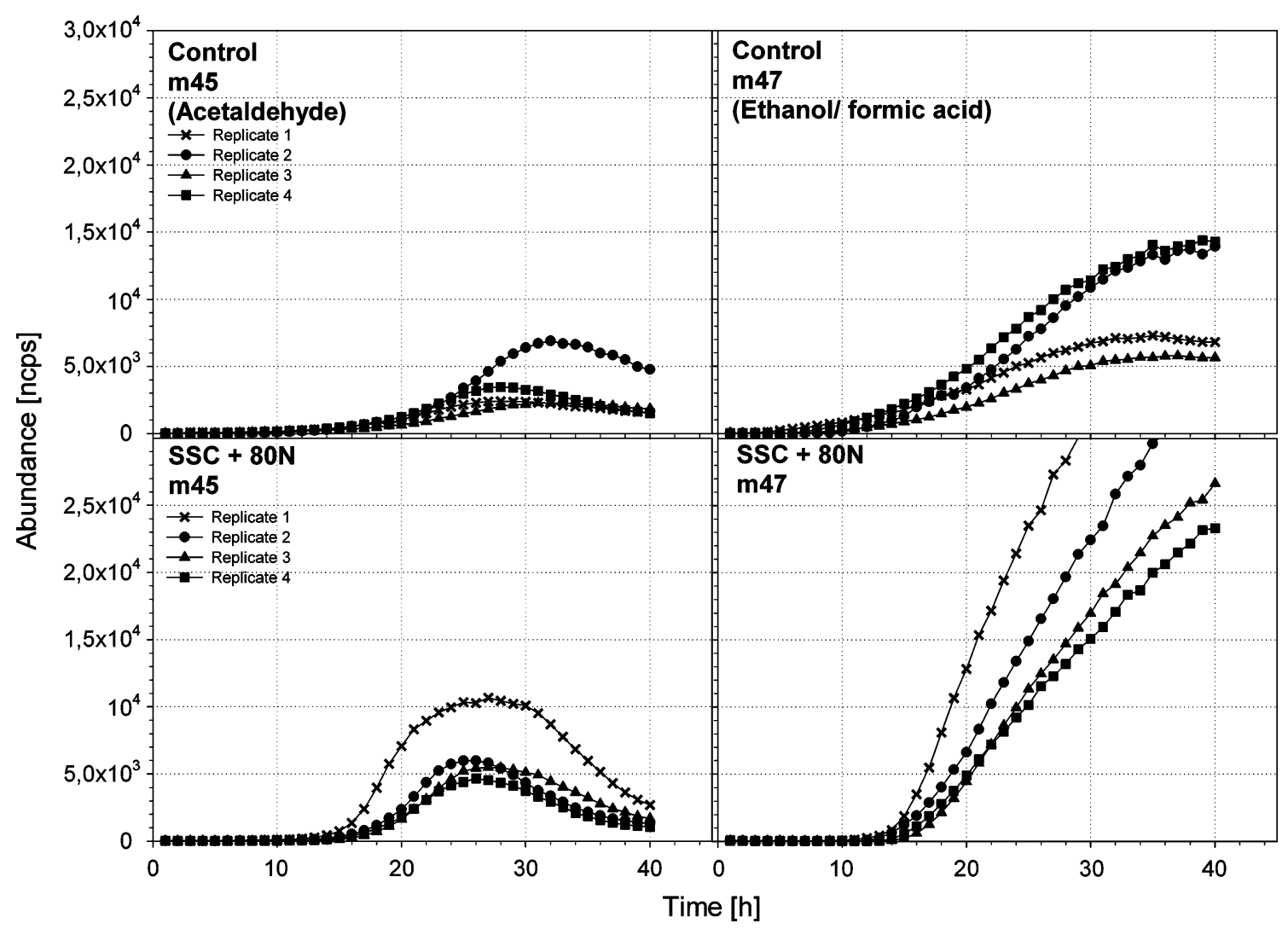

Fig. 5 Exemplary temporal charts of $\mathrm{m} 45$ (acetaldehyde) and $\mathrm{m} 47$ (ethanol and formic acid) of control and $\mathrm{SSC}+80 \mathrm{~N}$ replicates. The net VOC production rates of the replicates are varying considerably, but the curve shapes are similar within the treatment (control or SSC+

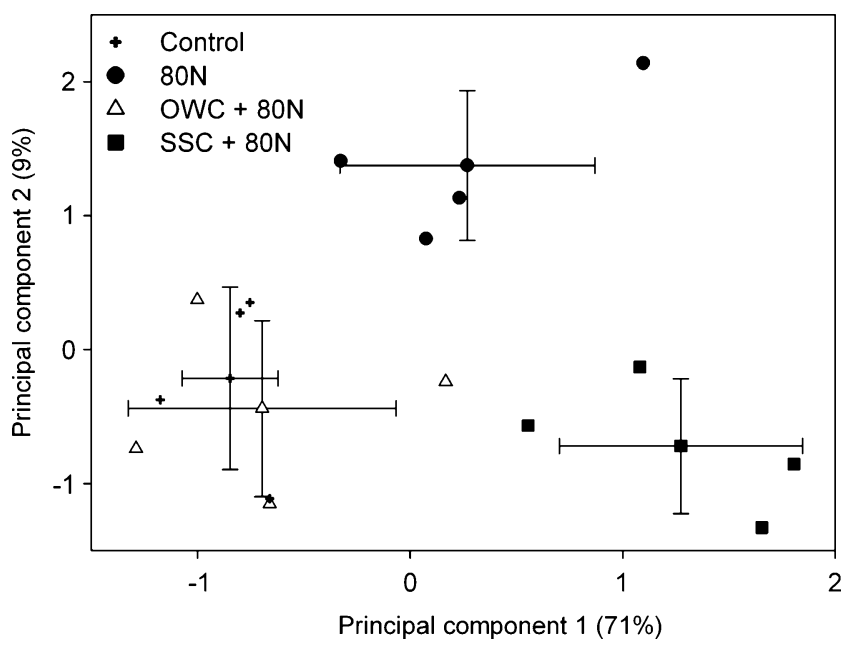

Fig. 6 Volatile organic compound emission patterns of differently treated soils visualised by a multidimensional scaling (MDS) diagram. Principal components of all significant masses are shown as dimensions 1 and 2 (cumulatively, explaining $80 \%$ of the variance). Group means and standard deviations are given
$80 \mathrm{~N})$. The curve shapes of $\mathrm{m} 45$ and $\mathrm{m} 47$ are different; $\mathrm{SSC}+80 \mathrm{~N}$ samples were found to produce more VOC, and in case of $\mathrm{m} 45$, the maximum was reached faster

relatively stable against treatment-driven influences. Differences in DGGE fingerprints were due to the occurrence of a few faint bands which were missing in other lanes, again denoting the weak influence of the different treatments. These findings confirm the results of Ros et al. (2006b) on the bacterial community structure of the same soil and treatments using 16SSU rDNA DGGE fingerprint analysis and of Innerebner et al. (2006) who found differences in ammonia-oxidising bacteria community structure.

Cluster analysis of both ITS and 18SSU fingerprints revealed highest similarities between the community structure of control and $\mathrm{OWC}+80 \mathrm{~N}$ samples. $80 \mathrm{~N}$ samples and $\mathrm{SSC}+80 \mathrm{~N}$ samples clustered separately, indicating a stronger influence of these treatments on fungal community. An explanation may be that $\mathrm{OWC}+80 \mathrm{~N}$ is (despite the nitrogen fertiliser content) a substrate similar to natural organic carbon sources (Crecchio et al. 2001; Pérez-Piqueres et al. 2005), whilst mineral fertiliser alone or SSC $+80 \mathrm{~N}$ are different from common organic matter sources and thus to a larger degree affect the microbial community structure (Tilman 1998; Pascual et al. 1997; Six et al. 1999; Kandeler et al. 2000). This may be linked to a slower nutrient release compared to mineral fertiliser and sewage sludge compost 
or to the lower heavy metal load of organic waste compared to sewage sludge compost. Mature organic waste compost contains predominantly organically bound nitrogen and stable organic matter, most of it only poorly accessible to microorganisms, somehow presenting a kind of natural amendment. It has been reported earlier that some soil treatments (e.g. municipal organic waste compost) take weaker influence on the composition of soil microbial community structure than edaphic conditions, temperature or soil depth (Crecchio et al. 2001; Pérez-Piqueres et al. 2005; Innerebner et al. 2006; Ros et al. 2006a, b). In contrast, the application of sewage sludge compost, consisting of faeces and wastewater-derived substances is an artificial intrusion in the soil ecosystem, supplying soil with unfamiliar compounds and nutrients. Similarly, the application of mineral fertilisers may change the substrates nutrient availability and as a consequence also microbial community structure of soils. Additionally, mineral fertilisers and sewage sludge composts are known to release nitrogen very fast (Insam and Merschak 1997; Tilman 1998; Pascual et al. 1997; Six et al. 1999), resulting in changes of microbial community structure.

\section{Basal respiration and microbial biomass}

Microbial biomass and basal respiration rates differed significantly between the control and SSC $+80 \mathrm{~N}$ treatments (Fig. 2). Compost-amended samples differed from noncompost-amended samples, showing elevated soil microbial activity and $C_{\text {mic }}$. Compost amendments contribute to the buildup of SOM (Lal 2005; Roldan et al. 2005; Ros et al. 2006a) and change the microbial degradability and the diversity of organic substrates, resulting in an increased microbial biomass and diversity (Insam 1990; Carter 1996). In contrast, mineral fertiliser amendment can deplete soil organic matter (Six et al. 1999; Ros et al. 2006a, b).

Our $C_{\text {mic }}$ and basal respiration rates were rather low in comparison with those of previous studies (Ros et al. 2006a, b), probably because our samples were taken in autumn when soil microbial activity usually declines (Bardgett et al. 1999), whereas Ros et al. (2006b) sampled their soils in spring. Our results confirm those by Ros et al. (2006b) who were able to show differences in $C_{\text {mic }}$ and basal respiration among the different treatments and a general decrease of these properties with soil depth. Another explanation for the lower $C_{\text {mic }}$ may be soil management effects since our samples were taken 7 days after ploughing, which changes the accessibility of organic matter and oxygen to the microbes (Stockfisch et al. 1999; Balesdent et al. 2000). Ploughing also mixes the lower soil layers low in microbial biomass with the upper soil layers. Despite $\mathrm{OWC}+80 \mathrm{~N}$ and control samples differing in microbial biomass values, their $\mathrm{VOC}$ production rates were similar (Fig. 2); it may be concluded that an increased VOC production in the $\mathrm{OWC}+80 \mathrm{~N}$ samples may have been accompanied by an increased consumption of VOCs. DGGE fingerprint analysis revealed high similarity between the control and $\mathrm{OWC}+80 \mathrm{~N}$ samples. In contrast, control and $80 \mathrm{~N}$ samples showed similar $C_{\text {mic }}$ but differed in VOC production rates. An explanation may be the induction of a priming effect that liberates carbon compounds from the indigenous soil pool (Blagodatskaya and Kuzyakov 2008).

\section{Microbial growth and VOC production}

Along with plant roots, microorganisms have been reported to be a major source of VOCs produced in soils (Stotzky and Schenk 1976; Stahl and Parkin 1996; Mackie and Wheatley 1999; Isidorov and Jdanova 2002; Leff and Fierer 2008; Kai et al. 2009; Insam and Seewald 2010). In contrast to this and despite microbial VOC production, plain soil (without plant roots) is reported to be a VOC sink, strongly dependent on soil temperature and moisture (Asensio et al. 2007a). Volatile organic compound sorption to clay minerals (Petersen et al. 1995; Chen and Wu 1998; Ruiz et al. 1998; Poulsen et al. 1998; Serrano and Gallego 2006), solubilisation in the soil aqueous phase (Asensio et al. 2007a) or degradation by other microorganisms (Cleveland and Yavitt 1998; Smolander et al. 2006; Owen et al. 2007; Insam and Seewald 2010) may explain any soil net VOC uptake or variations between replicates (Leff and Fierer 2008). Microbial VOCs may derive from many different metabolic sources, such as primary metabolism like end products of fermentative pathways such as ethanol (ethanol fermentation), butyric acid and acetone (butyric acid fermentation) and as volatile intermediates of aerobic or anaerobic detritus decomposition (Castaldelli et al. 2003; Karl et al. 2003). More complex VOCs, with a higher molecular weight, may derive from secondary metabolism pathways, such as production of signalling compounds or antibiotics (Mathivanan et al. 2008; Splivallo 2008). The low VOC emissions from the $\mathrm{OWC}+80 \mathrm{~N}$ samples (which were comparable to the VOC emissions of the control) may be due to a fast degradation of VOCs.

\section{Detection and identification of VOC}

Under anaerobic conditions, a much higher number and abundance of masses could be observed after glucose addition than under aerobic measurements or non-glucoseamended tests. This may be due to the fact that glucose addition-induced microbial activity entails fermentation of glucose and SOM. The end products of anaerobic fermentation (such as ethanol, methanol, butyric acid, acetone and formic acid) are highly volatile compounds produced rapidly in high amounts. In contrast, under aerobic 
conditions, the most efficient way of producing energy from glucose and soil substrates is aerobic respiration resulting in the release of carbon dioxide and water. The production of many other VOCs would start with the secondary metabolites. In comparison to the end products of the energy chain, secondary metabolites are produced in much lower amounts, thus being diluted in the steady flow of the PTR-MS carrier gas used in this investigation. Furthermore, VOCs produced under aerobic conditions may at the same time serve as energy source for VOCdegrading microorganisms (soil microbial food web), resulting in VOC mineralisation (Cleveland and Yavitt 1998; Owen et al. 2007).

Four masses were identified: $\mathrm{m} 33$ as methanol, m45 as acetaldehyde, m47 as formic acid and ethanol and m59 as acetone. For all other masses, literature information considered and additional PTR-TOF-MS measurements carried out suggest a tentative mass classification. As isotopes, multiple ionisation, molecule fragmentation and water or ion clustering lead to mass overlap, identification of masses from complex systems as soils remains a sophisticated task. The combined application of PTR-MS with TOF-MS helps to determine the molecular mass of the respective VOC to the first two decimal places. Therefore, it is possible to limit the chemical compound to its mass formula. Another option is to make use of the isotopic pattern of elements. Then, mass 48 appeared proportional to mass $47(2.3 \pm 0.38 \%)$, probably due to the presence of the carbon isotope ${ }^{13} \mathrm{C}$ (with a natural abundance of $1.1 \%$ ). For example, one molecule of ethanol contains two $\mathrm{C}$ atoms, leaving two possible positions for the integration of a ${ }^{13} \mathrm{C}$ isotope, giving a total chance of $2.2 \%$ for an incorporation of ${ }^{13} \mathrm{C}$. The remaining $0.1 \%$ may result from the incorporation of ${ }^{2} \mathrm{H}(6 \times 0.0115 \%)$ and ${ }^{17} \mathrm{O}(1 \times 0.038 \%)$. Previous investigations showed that compounds derived from molecular fragmentation contributed to masses 41, 43 and 69 in high concentrations (Mayr et al. 2003; Yeretzian et al. 2003; Ezra et al. 2004; Steeghs et al. 2004; Mayrhofer et al. 2006; Araghipour et al. 2008). In this investigation, these masses were also found in considerable amounts.

To date, only a few studies concerning VOC production from soil microorganisms have been conducted. Many of these studies applied GC-MS approaches with headspace accumulation techniques, thus mainly investigating VOCs with molecular weights $>100 \mu$, like limonene or pinene (Isidorov and Jdanova 2002; Asensio et al. 2007a; Leff and Fierer 2008; Insam and Seewald 2010). Many of these "heavy" VOCs are known to be intermediate products of plant residue degradation or secondary metabolites of microorganisms. In this investigation, with the aid of PTR-MS, masses below $100 \mu$ were detected in highest concentrations, some of the VOCs identified as end products of glucose fermentations (like ethanol, acetaldehyde or acetone). Therefore, we suppose that the VOCs measured mainly derived from glucose fermentation pathways, induced by glucose amendments. Thus, the applied measurement method reflects the microbial metabolism during anaerobic glucose fermentation.

Emission dynamics and comparison of VOC emission pattern

The absence of certain masses in the VOC emission pattern of the different treatments could be due to production rates yielding concentrations lower than the detection limit of PTR-MS (5 pptv). Mass spectra of $\mathrm{SSC}+80 \mathrm{~N}$ samples showed the highest number of masses (39, Fig. 4) and the highest VOC concentrations. The VOC emission patterns of the treatments $\mathrm{OWC}+80 \mathrm{~N}$ and control were the most similar. The differences in the dynamics of VOC production among samples may be attributed to several reasons. One possible explanation for the more rapid increase in the $\mathrm{SSC}+80 \mathrm{~N}$ samples compared to the control samples (Fig. 5) may be a shift of the microbial community from r- to K-strategists. On the other hand, it may also indicate a delayed response of VOC degraders in the case of the $\mathrm{SSC}+80 \mathrm{~N}$ samples. In any case, also these data support earlier findings that sewage sludge amendments have a strong impact on biological and biochemical processes in soil (e.g. Ros et al. 2006a).

Significant differences in peak maxima of some VOCs occurr between treatments. Principal component analysis of these masses visualised with multidimensional scaling resulted in a Euclidean distance matrix which showed the separation of the treatments into three clusters (Fig. 6). Here, $80 \mathrm{~N}$ and $\mathrm{SSC}+80 \mathrm{~N}$ samples clearly separated from each other and from $\mathrm{OWC}+80 \mathrm{~N}$ and control samples. Interestingly, it was not possible to distinguish between $\mathrm{OWC}+80 \mathrm{~N}$ and control samples using PTR-MS measurements. This may be due to the high similarity in the fungal community structure of these two treatments as denoted by DGGE fingerprint analysis where control and $\mathrm{OWC}+80 \mathrm{~N}$ samples clustered (Fig. 1).

\section{Conclusion and outlook}

Differences in overall soil VOC emission patterns could be detected by PTR-MS measurement, showing the power of PTR-MS of being a valuable tool for the online monitoring of certain metabolic activities of soil microbial communities. However, the online measurement requires the steady flow of carrier gas, and this can lead to the dilution and enhanced decomposition of the VOC trace gases. In this investigation, we tried to overcome this problem by enhancing VOC production through glucose amendment and anaerobic measurements. Greater sample volume (here 
$170 \mathrm{ml}$ ) could help to increase VOC production to measurable amounts. Direct sampling of evolved soil gas using evacuated silica-coated canes could, in future studies, help to overcome sample pretreatment and connected biases.

In our study, $\mathrm{SSC}+80 \mathrm{~N}$ and $80 \mathrm{~N}$ have not only the strongest impact on microbial community composition but also on VOC emission patterns. Specific tracer VOC could not be identified with the approaches used, but direct gas sampling could help to find less abundant compounds that are produced by a small group of microorganisms and under field conditions.

In this study, we were able to identify compounds occurring with masses 33 (methanol), 45 (acetaldehyde), 47 (ethanol), and 59 (acetone; confirmed by PTR-TOF-MS). Further studies should aim at identifying compounds contributing to masses like 41,43 and 69. In this investigation, no "marker mass" could be identified for any of the four different soil treatments. Future efforts should aim at a PTR-MS-linked identification of the detected masses to be able to draw conclusions on the microorganisms and on their physiological state.

Acknowledgements This study was funded by FWF (Austrian Science Fund). We are grateful to K. Aichberger and A. Aichinger (Austrian Agency for Health and Food Safety, AGES) for setting up and maintaining the experimental site. We also express our gratitude to M. Goberna, J. Seeber and G. Seeber for their statistical support and to M. Bonfanti for supplying background data.

Open Access This article is distributed under the terms of the Creative Commons Attribution Noncommercial License which permits any noncommercial use, distribution, and reproduction in any medium, provided the original author(s) and source are credited.

\section{References}

Anderson JPE, Domsch KH (1978) A physiological method for the quantitative measurement of microbial biomass in soils. Soil Biol Biochem 10:215-221

Araghipour N, Colineau J, Koot A, Akkermans W, Rojas JMM, Beauchamp J, Wisthaler A, Märk TD, Downey G, Guillou C, Mannina L, van Ruth S (2008) Geographical origin classification of olive oils by PTR-MS. Food Chem 108:374-383

Asensio D, Penuelas J, Filella I, Llusià J (2007a) On-line screening of soil VOCs exchange responses to moisture, temperature and root presence. Plant Soil 291:249-261

Asensio D, Penuelas J, Llusià J, Ogaya R, Filella I (2007b) Interannual and interseasonal soil $\mathrm{CO}_{2}$ efflux and $\mathrm{VOC}$ exchange rates in a Mediterranean holm oak forest in response to experimantal drought. Soil Biol Biochem 39:2471-2484

Balesdent J, Chenu C, Balabane M (2000) Relationship of soil organic matter dynamics to physical protection and tillage. Soil Tillage Res 53:215-230

Bardgett RD, Lovell RD, Hobbs PJ, Jarvis SC (1999) Seasonal changes in soil microbial communities along a fertility gradient of temperate grasslands. Soil Biol Biochem 31:1021-1030
Bastias BA, Xu Z, Cairney JWG (2006) Influence of long-term repeated prescribed burning on mycelial communities of ectomycorrhizal fungi. New Phytol 172:149-158

Blagodatskaya E, Kuzyakov Y (2008) Mechanisms of real and apparent priming effects and their dependence on soil microbial biomass and community structure: critical review. Biol Fertil Soils 45:115-131

Börjesson T, Stollman U, Schnürer J (1990) Volatile metabolites and other indicators of Penicillium aurantiogriseum growth on different substrates. Appl Environ Microbiol 56:3705-3710

Börjesson T, Stollman U, Schnürer J (1992) Volatile metabolites produced by six fungal species compared with other indicators of fungal growth on cereal grains. Appl Environ Microbiol 58:2599-2605

Bunge M, Araghipour N, Mikoviny T, Dunkl J, Schnitzhofer R, Hansel A, Schinner F, Wisthaler A, Margesin R, Märk TD (2008) On-line monitoring of microbial volatile metabolites by proton transfer reaction-mass spectometry. Appl Environ Microbiol 74:2179-2186

Carter MR (1996) Analysis of organic matter storage in agroecosystems. In: Carter MR, Stewart BA (eds) Structure and organic matter storage in agricultural soils. CRC, Boca Raton, pp 3-14

Castaldelli G, Welsh DT, Flachi G, Zucchini G, Colombo G, Rossi R, Fano EA (2003) Decomposition dynamics of the bloom forming macroalga Ulva rigida $\mathrm{C}$. Agardh determinded using a ${ }^{14} \mathrm{C}$-carbon radio-tracer technique. Aquat Bot 75:111-122

Chan KY, Heenan DP, Oates A (2002) Soil carbon fractions and relationship to soil quality under different tillage and stubble management. Soil Tillage Res 63:133-139

Chen C-Y, Wu S-C (1998) The influence of relative humidity on the adsorption of toluene by soils - interpretation with the adsorption energy distribution functions. Chemosphere 37:14371444

Cleveland CC, Yavitt JB (1998) Microbial consumption of atmospheric isoprene in a temperate forest soil. Appl Environ Microbiol 64:172-177

Crecchio C, Curci M, Mininni R, Ricciuti P, Ruggiero P (2001) Shortterm effects of municipal solid waste compost amendments on soil carbon and nitrogen content, some enzyme activities and genetic diversity. Biol Fertil Soils 34:311-318

Dickschat JS, Helmke E, Schulz S (2005a) Volatile organic compounds from arctic bacteria of the Cytophaga-FlavobacteriumBacterioides group: a retrobiosynthetic approach in chemotaxonomic investigations. Chem Biodivers 2:318-353

Dickschat JS, Martens T, Brinkhoff T, Simon M, Schulz S (2005b) Volatiles released by a Streptomyces species isolated from the North Sea. Chem Biodivers 2:837-865

Ezra D, Jasper J, Todd R, Knighton B, Grimsrud E, Strobel G (2004) Proton transfer reaction-mass spectrometry as a technique to measure volatile emissions of Mucodor albus. Plant Sci 166:1471-1477

Fiedler K, Schütz E, Geh S (2001) Detection of microbial volatile organic compounds (MVOCs) produced by moulds on various materials. Int J Hyg Environ Health 204:111-121

Fischer G, Dott W (2003) Relevance of airborne fungi and their secondary metabolites for environmental occupation and indoor hygiene. Arch Microbiol 179:75-82

Fischer G, Schwalbe R, Möller M, Ostrowski R, Dott W (1999) Species-specific production of microbial volatile organic compounds (MVOC) by airborne fungi from a compost facility. Chemosphere 39:795-810

Gao P, Martin J (2002) Volatile metabolites produced by three strains of Stachybotrys chartarum clutivated on rice and gypsum board. J Occup Environ Hyg 17:430-436 
Garcia C, Hernandez T, Costa F, Ceccanti B (1994) Biochemical parameters in soil regenerated by addition of organic wastes. Waste Manage Res 12:457-466

Hansel A, Jordan A, Holzinger R, Prazeller P, Vogel W, Lindinger W (1995) Proton transfer reaction mass spectometry: on-line trace gas analysis at the ppb level. Int J Mass Spectrom 149:609619

Hansel A, Jordan A, Warneke C, Holzinger R, Lindinger W (1998) Improved detection limit of the proton-transfer reaction mass spectrometer: on-line monitoring of volatile organic compounds at mixing ratios of a few pptv. Rapid Commun Mass Spectrom $12: 871-875$

Heinemeyer O, Insam H, Kaiser EA, Walenzik G (1989) Soil microbial biomass and respiration measurements: an automated technique based on infrared gas analysis. Plant Soil 116:77-81

Innerebner G, Knapp B, Vasara T, Romantschuk M, Insam H (2006) Traceability of ammonia-oxydizing bacteria in compost-treated soils. Soil Biol Biochem 38:1092-1100

Insam H (1990) Are the soil microbial biomass and basal respiration governed by the climatic regime? Soil Biol Biochem 22:525-532

Insam H, Merschak P (1997) Nitrogen leaching from forest soil cores after amending organic recycling products or fertilizers. Waste Manage Res 15:277-292

Insam H, Seewald MSA (2010) Volatile organic compounds (VOCs) in soils. Biol Fert Soil 46. doi:10.1007/s00374-010-0442-3

Isidorov V, Jdanova M (2002) Volatile organic compounds from leaves litter. Chemosphere 48:975-979

Kai M, Haustein M, Molina F, Petri A, Scholz B, Piechulla B (2009) Bacterial volatiles and their action potential. Appl Microbiol Biotechnol 81:1001-1012

Kandeler E, Tscherko D, Bruce KD, Stemmer M, Hobbs PJ, Bardgett RD, Amelung W (2000) Structure and function of the soil microbial community in microhabitats of a heavy metal polluted soil. Biol Fertil Soils 32:390-400

Karl T, Guenther A, Spirig C, Hansel A, Fall R (2003) Seasonal variation of biogenic VOC emissions above a mixed hardwood forest in northern Michigan. Geophys Res Lett 30:2186

Kershi G, Magan N, Voysey P (1998) Use of an electronic nose for the early detection and differentiation between spoilage fungi. Lett Appl Microbiol 27:261-264

Lal R (2005) Soil carbon sequestration for sustaining agricultural production and immproving the environment with particular reference to Brazil. J Sustain Agric 26:23-42

Larsen TO, Frisvad JC (1995a) Characterization of volatile metabolites from 47 Penicillium taxa. Mycol Res 99:1153-1166

Larsen TO, Frisvad JC (1995b) Chemosystematics of Penicillium based on profiles of volatile metabolites. Mycol Res 99:1167-1174

Leff JW, Fierer N (2008) Volatile organic compound (VOC) emissions from soil and litter samples. Soil Biol Biochem 40:1629-1636

Legendre L, Legendre P (1998) Numerical ecology, 2nd edn. Elsevier Science B. V, Amsterdam, p 853

Lindinger W, Hansel A, Jordan A (1998) On-line monitoring of volatile organic compounds at ppt levels by means of protontransfer-reaction mass spectometry (PTR-MS) medical applications, food control and environmental research. Int $\mathrm{J}$ Mass Spectrom 173:91-241

Linton CJ, Wright SJL (1993) Volatile organic compounds: microbiological aspects and some technological implications. J Appl Bacteriol 75:1-12

Mackie AE, Wheatley RE (1999) Effects and incidence of volatile organic compound interactions between soil bacterial and fungal isolates. Soil Biol Biochem 31:375-385
Mathivanan N, Prabavathy VR, Vijayanandraj VR (2008) The effect of fungal secondary metabolites on bacterial and fungal pathogens. In: Karlovsky P (ed) Secondary metabolites in soil ecology. Soil biology 14. Springer, Berlin, pp 129-140

Matysik S, Herbarth O, Mueller A (2008) Determination of volatile metabolites originating from mould growth on wall paper and synthetic media. J Microbiol Methods 75:182-187

Mayr D, Margesin R, Klingsbichel E, Hartungen E, Jenewein D, Schinner F, Märk TD (2003) Rapid detection of meat spoilage by measuring volatile organic compounds by using proton transfer reaction mass spectrometry. Appl Environ Microbiol 69:46974705

Mayrhofer S, Mikoviny T, Waldhuber S, Wagner AO, Innerebner G, Franke-Whittle MTD, Hansel A, Insam H (2006) Microbial community related to volatile organic compound (VOC) emission in household biowaste. Environ Microbiol 8:1960-1974

Muyzer G, De Waal EC, Uitterlinden AG (1993) Profiling of complex microbial populations by denaturing gradient gel electrophoresis analysis of polymerase chain reaction-amplified genes coding for 16S rRNA. Appl Environ Microbiol 59:695700

Owen S, Clark S, Pompe M, Semple KT (2007) Biogenic volatile organic compounds as potential carbon sources for microbial communities in soil form the rhizosphere of Populus tremula. FEMS Microbiol Lett 268:34-39

Pascual JA, Hernandez T, Ayuso M, Garcia C (1997) Changes in the microbial activity of arid soils amended with urban organic wastes. Biol Fertil Soils 24:429-434

Pérez-Piqueres A, Edel-Hermann V, Alabouvette C, Steinberg C (2005) Response of soil microbial communities to compost amendments. Soil Biol Biochem 38:460-470

Petersen LW, Jacobsen OH, Moldrup P (1995) The effect of moisture and soil texture on the adsorption of organic vapors. J Environ Qual 24:752-759

Poulsen TG, Modlrup P, Yamaguchui T, Massmann JW, Hansen JA (1998) VOC vapor sorption in soil: soil type dependent model and implications for vapor extraction. J Environ Eng 124:146155

Roldan A, Salinas-Garcia JR, Alguacil MM, Caravaca F (2005) Changes in soil enzyme activity, fertility, aggregation and $\mathrm{C}$ sequesteration mediated by conservation tillage practices and water regime in a maize field. Appl Soil Ecol 30:11-20

Ros M, Klammer B, Knapp B, Aichberger K, Insam H (2006a) Longterm effects of compost amendment of soil on functional and structural diversity and microbial activity. Soil Use Manage 22:209 218

Ros M, Pascual JA, Garcia C, Hernandez MT, Insam H (2006b) Hydrolase activities, microbial biomass and bacterial community in a soil after long-term amendment with different composts. Soil Biol Biochem 38:3443-3452

Rose LJ, Simmons RB, Crow SA, Ahearn DG (2000) Volatile organic compounds associated with microbial growth in automobile air conditioning systems. Curr Microbiol 41:206-209

Ruiz J, Bilbao R, Murillo MB (1998) Adsorption of different VOC onto soil minerals from gas phase: influence of mineral, type of VOC, and air humidity. Environ Sci Technol 32:1079- 1084

Sanguinetti CJ, Dias Neto E, Simpson AJG (1994) Rapid silver staining and recovery for PCR products separated on polyacrylamide gels. Biotechniques 17:914-921

Schade GW, Custer TG (2004) OVOC emissions from agricultural soil in northern Germany during the 2003 European heat wave. Atmos Environ 38:6105-6114

Schnürer J, Olsson J, Börjesson T (1999) Fungal volatiles as indicators of food and feeds spoilage. Fungal Genet Biol 27:209-217 
Serrano A, Gallego M (2006) Sorption study of 25 volatile organic compounds in several Mediterranean soils using headspace-gas chromatography-mass spectrometry. J Chromatogr A 1118:261270

Six J, Elliot ET, Paustian K (1999) Aggregate and soil organic matter dynamics under conventional and no-tillage systems. Soil Sci Soc Am J 63:1350-1358

Smet E, Van Langenhove H, De Bo I (1999) The emissions of volatile compounds during the aerobic and the combined anaerobic/ aerobic composting of biowaste. Atmos Environ 33:1295-1303

Smolander A, Ketola RA, Kotiaho T, Kanerva S, Suominen K, Kitunen V (2006) Volatile monoterpenes in soil atnosphere under birch and conifers: effects on soil $\mathrm{N}$ transformations. Soil Biol Biochem 38:3436-3442

Splivallo R (2008) Biological significance of truffle secondary metabolites. In: Karlovsky P (ed) Secondary metabolites in soil ecology. Soil biology 14. Springer, Berlin, pp 141-165

Stahl PD, Parkin TB (1996) Microbial production of volatile organic compounds in soil microcosms. Soil Sci Soc Am J 60:821-828

Steeghs M, Bais HP, deGouw J, Goldan P, Kuster W, Northway M, Fall R, Vivanco JM (2004) Proton-transfer-reaction mass spectrometry as a new tool for real time analysis of root-secreted volatile organic compounds in Arabidopsis. Plant Physiol 135:47-58
Stockfisch N, Forstreuter T, Ehlers W (1999) Ploughing effects on soil organic matter after twenty years of conservation tillage in Lower Saxony, Germany. Soil Tillage Res 52:91-101

Stotzky G, Schenk S (1976) Volatile organic compounds and microorganisms. Crit Rev Microbiol 4:333-382

Tilman D (1998) The greening of the green revolution. Nature 396:211-212

Tirranen LS, Gitelson II (2006) The role of volatile metabolites in microbial communities of the LSS higher plant link. Adv Space Res 38:1227-1232

Vainio EJ, Hantula J (2000) Direct analysis of wood-inhabiting fungi using denaturing gradient gel electrophoresis of amplified ribosomal DNA. Mycol Res 104:927-936

Wheatley R, Hackett C, Bruce A, Kundzewicz A (1997) Effect of substrate composition on production of volatile organic compounds from Trichoderma spp. inhibitory to wood decay fungi. Int Biodeterior Biodegrad 39:199-205

Wilkins K, Larsen K, Simkus M (2000) Volatile metabolites from mould growth on building materials and synthetic media. Chemosphere 41:437-446

Yeretzian C, Jordan A, Lindinger W (2003) Analysing the headspace of coffee by proton-transfer-reaction mass spectrometry. Int $\mathrm{J}$ Mass Spectrom 223:115-139 